\title{
The Experience of Australia's First Nations Men Supporting Their Partners During Childbirth: A Descriptive, Interpretive Study
}

\author{
Yordanka Berg Blanc and Elaine Dietsch
}

\begin{abstract}
This research explored and described the experiences of Australia's First Nations expectant fathers as they supported their partners during childbirth. A descriptive, interpretive approach used purposive recruitment to the point of data saturation. Five participants were interviewed within 4 days of supporting their partners during childbirth. Interview data were thematically analyzed, and five themes emerged. Three themes were consistent with findings from non-First Nations fathers. Two new themes related to changes in childbearing traditions, "we show affection in different way" and staff support strategies, "educate dads by telling stories about birth"; will be closely examined in this article. This research identified the existence of a new generation of First Nations fathers in Central Australia wishing to guide and support their partners in their journey to parenthood. The development of support programs, responsive to their unique ways of knowing and learning style, will ensure that their needs are optimally met.
\end{abstract}

KEYWORDS: Australia’s First Nations expectant fathers; culture; support; childbirth

\section{INTRODUCTION}

There is increasing evidence identifying the positive effects of partner's involvement during childbirth in achieving good outcomes for women and their babies, including weight gain in premature newborns, longer breastfeeding duration, better academic achievement, higher self-esteem and less antisocial behaviour in offspring later in life, and lower rates of maternal depression and anxiety (Bar-Yam \& Darby, 1997; Buist, Morse, \& Durkin, 2003; Coutinho et al., 2016; Pryor, Morton, Bandara, Robinson, \& Grant, 2014).

Researchers have explored the experience of expectant fathers across the world over the last three decades (Bäckström \& Hertfelt, 2011; Buist et al., 2003; Coutinho et al., 2016; Kakaire, Kaye, \& Osinde, 2011; Machin, 2015; Vehviläinen-Julkunen \& Liukkonen, 1998). However, sparse research into the experience of Australia's First Nations expectant father's experience during childbirth may mirror the lack of culturally appropriate maternity care that is responsive to the unique needs, interest,s and ways of knowing of Australia's First Nations childbearing women and their partners. It is likely that maternity services based on Euro-western, biomedical models might be unsuitable for many Australia's First Nations women and their male partners, especially for those living in poverty, with limited literacy and substandard or no housing (Ball, 2010; Durey \& Thompson, 2012; Kildea, Tracy, Sherwood, MagickDennis, \& Barclay, 2016).

In this article, the term First Nations is used to refer to Australian Aboriginal and Torres Strait Islander people and to acknowledge that they have been on the continent for many tens of thousands of years prior to European colonization (Sovereign Union, 2016). The term birthing on country is the expression used to acknowledge that Australia’s First Nation people embrace traditional practices in order to keep childbearing women and newborns connected with their ancestor's land, known as "Country" (Kildea et al., 2017). 
As more First Nations pregnant women are requesting their partner's companionship in the birthing room (Carter, Lumley, Wilson, \& Bell, 2004; Reibel, Morrison, Griffin, Chapman, \& Woods, 2015; Simmonds et al., 2012), the aim of this research was to describe the experiences of Australia's First Nations expectant fathers supporting their partners during childbirth by exploring four questions during each interview: What are the challenges that First Nations fathers encounter while supporting their partners during childbirth? What are the best experiences that First Nations fathers' encounter while supporting their partners during childbirth? From the perspective of First Nations fathers, what aspects of the support provided to them should be given more attention? Why are more First Nations men supporting their partners during childbirth?

\section{BACKGROUND}

Studies conducted in non-First Nations populations (Hildingsson, Cederlöf, \& Widén, 2011; Hollins, 2008; Howarth, Scott, \& Swain, 2017; Kululanga, Malata, Chirwa, \& Sundby, 2012; Ledenfors \& Berterö, 2016; Sapkota, Kobayashi, \& Takase, 2012), reported that fathers expressed satisfaction regarding the service provided by the midwife and acknowledged that they were kept informed of how labor was progressing. In contrast, studies exploring Australia’s First Nations women's and their partners' experiences of midwifery support reported institutional racism (Brown, Middleton, Fereday, \& Pincombe, 2016). Furthermore, Dietsch, Shackleton, Davies, Alston, and McLeod (2010) and Dietsch et al., (2011) reported midwifery bullying of Australian First Nations women and their partners.

This research was conducted in the maternity unit of the major regional hospital in Central Australia with the purpose of illuminating contemporary experiences of First Nations men while supporting their partners during labor and birth. The maternity unit is classified as a level five facility, according to the Capability Framework classification (Australian Health Ministers' Advisory Council, 2013). The hospital provides health service to approximately 60,000 people in a geographical AQ1 area covering more than 872,000 square kilometers (Australian Institute of Health and Welfare [AIHW], 2018), an area larger than Germany, Italy, Austria, Switzerland, the Netherlands, and Belgium combined (Nation Master, 2018). The next closest tertiary level hospital is nearly 1,400 kilometers away and the nearest hospital providing birthing services is over 1,100 kilometers away. Approximately, 800 women birth each year at this regional hospital (Northern Territory Government, 2017). Furthermore, women living in remote areas are required to travel into the town at 38 weeks gestation and stay there until their baby is born (AIHW, 2018).

Australia's First Nations women in Central Australia have the option of standard care through Congress Alukura, shared maternity care between the obstetrician and hospital midwives and continuity of midwifery care through the Midwifery Group Practice (MGP) (Carroll \& Lack, 2013). Women meeting strict criteria also have the option of planning to birth at home.

According to Carroll and Lack (2013), 30\% of Australia's First Nations women are supported by the MGP in the region and during the period March 2009 to December 2012, 1\%-2\% of this population experience homebirth in the town. First Nations women are less likely to birth vaginally and more likely to require an emergency cesarean section than non-First Nations women (Hall, Case, \& O’Neill, 2015).

\section{METHODS}

\section{Overview}

Institutional ethics committee approval was sought and received from the Central Australian Human Research Ethics Committee (HREC-16-447). Ethical consideration and approval were also provided by the Executive Director of Medical and Clinical Services and the Maternity Unit Manager of the hospital. Most importantly, ethical insight and guidance was sought and provided by the matriarchs in the Aboriginal community, anthropologists, and the Central Australia Aboriginal Congress Board of Directors.

A descriptive, interpretive method, as espoused by Smythe (2012), was selected for the research study. This methodology provided the best framework to capture the richness of Australia's First Nations expectant father's experience in their own words. As a result, the researchers learned from their experience, thematically analyzed the data provided and presented a simple but thought-provoking overview of their stories.

\section{Participants}

The participant's age ranged between 20 and 33 years old with an average age of 24 . Two participants were from the 
same town as the regional hospital where their partners birthed, one was from a rural area and two were from remote, isolated communities. Two participants had previous experience supporting their partners during childbirth and three were experiencing the event for the first time. Three participants had some high school education (average 11 years education) but two participants could not recall their educational level. Four participants were currently employed, and one was searching for employment. All participants spoke English as a second language. Three participants supported their partners during vaginal birth and two of them attended their partner's elective cesarean section under spinal anesthesia.

Purposive sampling techniques were used to recruit participants within 4 days of supporting their partners to birth. In line with Etikan, Musa, and Alkassim (2016), this approach was chosen because it enabled the researchers to select a sample based on the purpose of the study and the exclusive characteristics of those individuals whose experience was sought. Recruitment occurred until data saturation was realized following the interview with the fifth participant.

Semistructured interviews, lasting 30-60 minutes, were conducted face to face with each of the participants. The four interview questions cited above framed, but did not dictate, the interview flow which was primarily conversational in nature.

Permission to audiorecord the interviews was sought from each participant, but none of them consented to the audiorecording. The participants expressed concern about being recorded while speaking about such a private experience. All participants were, however, very happy for the interviewer (the principal researcher) to make short notes during the discussion. These notes were shared with the participants shortly after each interview as a means of member checking to ensure no detail was missed, misinterpreted, or misrepresented.

With the participant's permission, the principal researcher kept a self-reflective journal throughout the research process that was of invaluable assistance in the identification of emerging themes from the interviews. The handwritten notes taken during the interview and the consequent self-reflective journal entries guided the data analysis and emergence of themes. The data analysis process was informed by Abalos, Rivera, Locsin, and Schoenhofer (2016).

\section{RESULTS}

Five themes emerged from the data. Three (feelings toward childbirth attendance, support to women during childbirth, emotional experience during the journey) were consistent with studies conducted in non-First Nations populations (Carlson, Edleson, \& Kimball, 2014; Kaye et al., 2014). Two new themes emerged and these will be the focus in the article. The first new theme related to changes in childbearing traditions, "we show affection in different way," and the second theme analyzed the participant's reflections on staff support strategies, "educate dads by telling stories about birth."

\section{We Show Affection in Different Way: Changes in Childbearing Traditions}

Most participants in this study opted to be present during childbirth at the request of their partners and spoke passionately about wanting to be present. Opinions about why more Australia's First Nations men might be supporting their partners in labor were explored and their responses included, "because they care about the woman and kids"; "it is a special moment"; and "we show affection in different way, different growing."

Participants described their overall experience in a way that suggests joy, but also uncertainty as their generation of expectant fathers is the first to be present with their partners during labor and birth. The participants struggled witnessing their partners in pain while feeling unable to help as illustrated by the following extracts, "waiting long time for baby to come"; "seeing her in pain"; "seeing her in pain, not knowing what to do"; and "the whole process [was difficult]." One coping strategy was commonly used by the participants, "my only condition was to go out of the room for fresh air and have a break when I need it." Nevertheless, all participants in this study comforted their partners during labor and birth and reported that, "I rubbed her back," "I hold her hand," "I talked to her,"

The happiest and most memorable experiences described by the participants were "when baby comes," "watching her strength," "baby coming," "seen baby."

The participants described the childbirth as "full on" and "exciting" and none expressed regret about being present for the birth of their baby. 


\section{Educate Dads by Telling Stories About Birth: Reflections on Staff Support}

All participants reported feeling valued and appreciated the support they received from the midwives during their partner's labor and birth. Nevertheless, some participants expressed their desire to be better prepared to support their partners, to ease their fear, anxieties, and concern about the unknown childbirth journey. All participants believed the midwives could better facilitate this preparation and strongly felt that more attention should be paid to prepare Australia's First Nations expectant fathers for their supportive role. For example, participants shared that, "giving the partners something to eat or drink"; "talking to men as things go"; "it is important for dads to stay with the woman"; "giving options"; "midwife reassure, explain what is happening"; and "someone to talk to before coming here" would all have been useful midwifery support strategies. Another participant suggested a culturally appropriate strategy that midwives could use to provide better support, "we are very good observers. . . you know, educate dads by telling stories about birth."

\section{DISCUSSION}

Male partner's presence in any birthing environment is a relatively recent phenomenon. It was only in the 1970 s that male partners were regularly permitted and then encouraged to support their partners in Australian birthing suites (Dlugosz, 2013) and in all western maternity units (Prichep, 2017).

Even though male partner support during the birth is now the norm, their presence continues to invite the occasional controversy (Odent, 2009; Premberg, Carlsson, Hellstr囚m, \& Berg, 2011). Odent (2009) argued that it is not conducive to women's well-being, their endogenous hormone secretion, and progress of labor to have male partners present. In addition, Premberg et al. (2011) argued that when men enter the female area, the traditional gender order of power and control might reverse. The woman is pivotal, and the man's position is subordinated (Premberg et al., 2011).

In both precolonization European and Australia's First Nations culture, childbirth was traditionally an arena of women's sole responsibility and the spiritual dimension is added to the Australia's First Nations women's experience in that labor and birth are traditionally considered "sacred women's business" (Bell, 1998; Luo, Kueh, Jeffery, Petersen, \& Quinlivan, 2014;
Nappaljari, 2013). Therefore, it is very unlikely that Australia's First Nations men have experienced intergenerational role-modeling related to being present when their baby is born. Nevertheless, the evolving expectation that men will support their birthing partners, along with the increasing trend toward birthing away from country (Brown et al., 2016; Parker, McKinnon, \& Kruske, 2014; Reibel et al., 2015; Varcoe, Brown, Calam, Harvey, \& Tallio, 2013) may be transforming the role of Australia's First Nations expectant fathers in the childbirth process.

Hartz and McGrath (2017), Kululanga et al., (2012), de Melo and de Brito (2013), and Howarth et al., (2017) acknowledged that expectant father's identity; respect; care for their partner, their children, and their communities grow stronger when they have been present with their partners during labor and birth. There are arguments both for and against partners being present during labor and birth. Whichever are the more accurate, Australia's First Nations women and their partners, as individuals, are in the best position to know whether being present during labor and birth is in their interests.

The findings of this study suggest that the presence of Australia's First Nations fathers in the birthing suite was influenced by the woman's request as she felt more comfortable being supported by her partner. From observation, more First Nations men in Central Australia are supporting their partners during labor and birth than ever before.

An experience commonly described by participants in this study included the adaptive strategy of leaving the birthing room when the woman was continuously vocalizing with the surge of the contractions and returning to the room when she was more comfortable or less distressed. This finding shows a coping mechanism that has not been previously reported in the reviewed literature and warrants more investigation in the future.

All participants comforted their partners during labor and birth. Their descriptions are consistent with other studies (Eggermont, Beeckman, Hecke, Delbaere, \& Verhaeghe, 2017; Johansson et al., 2015; Longworth, Furber, \& Kirk, 2015; Longworth \& Kingdon, 2011; Sapkota et al., 2012) which confirm the father's ability to provide physical and emotional support during labor and birth.

It is unknown whether the participants in this study comforted their partners intuitively or when they received guidance from midwives. However, it can be implied that they might have perceived the woman's physical pain more legitimate than emotional distress. These findings are congruent with a body of research $(\mathrm{He}$ et al., 2015; Howarth et al., 2017; Kululanga et al., 2012; 
Ledenfors \& Berterö, 2016) that consistently described the feeling of helplessness expressed by expectant fathers irrespective of race, ethnicity, or socioeconomic status when they witnessed their partner's distress.

Within the context of the childbirth experience all participants acknowledged the woman's strengths while working with the pain of labor contractions. Similar findings are also reported by Kululanga et al. (2012) in a Malawian study where men acknowledged that their involvement in childbirth strengthened their relationship with their partners and children, increasing their love and respect toward them. The same claims were made by de Melo and de Brito (2013) in their descriptive and exploratory investigation, about Brazilian father's perception of their presence in the labor room during their child's birth, and Howarth et al. (2017) in a study conducted with New Zealand fathers.

The participants didn't hesitate in their affirmative response when they were asked if they would support their women again. This motivation may be an example of a healthy outcome of acculturation described by David, Aslan, Siedentopf, and Kentenich (2009) in their study of ethnic Turkish men supporting their partner birthing in Germany. Similar cultural integration and variation pertaining male involvement in childbirth were reported in studies conducted in South Africa (Sengane, 2009), Malawi (Kululanga et al., 2012), and Nepal (Sapkota et al., 2012).

While traditionally, Australia's First Nations men have had a limited role in birth matters (Bell, 1998; Luo et al., 2014), it might be inferred from the findings of this research that the involvement of the partner in the birthing process may maximize the lifelong well-being of the family and the long-term gains for their communities. However, these advantages are yet to be explored in a larger and more comprehensive study involving Australia's First Nations people before similar benefits could be ascertained.

This study revealed that all participants valued the support received from the midwives. While this is in keeping with studies related to non-First Nations fathers (Hildingsson et al., 2011; Hollins, 2008; Howarth et al., 2017; Kululanga et al., 2012; Ledenfors \& Berterö, 2016; Sapkota et al., 2012), it contrasts with findings of institutional racism (Brown et al., 2016) and midwifery bullying of First Nations women and their partners (Dietsch et al., 2010, 2011).

The incongruence between the earlier studies and this current research could possibly be explained by several factors, including but not limited to the fact that the current investigation was conducted in a slightly later time frame than earlier published studies (Dietsch et al., 2010, 2011) and midwives may be developing more culturally safe practice. However, the study by Brown et al. (2016) is more contemporaneous and does not support this explanation. A second possibility is that both Dietsch et al. $(2010,2011)$ studies were conducted in New South Wales and the Brown et al. (2016) study was conducted in South Australia, rather than in Central Australia. Therefore, there may be a geographical explanation related to midwifery support. Nevertheless, the more likely explanation is that the principal researcher and interviewer was known to be a midwife in the same hospital where the participants had supported their partners to birth only days before. This knowledge may have inhibited the participants from sharing any negative experience about midwifery support. Such a limitation would need to be considered in future studies.

Despite appreciating the midwifery support they received, participants in this study expressed their desire to be better prepared to support their partners and they believed midwives could facilitate this. A systematic review by Beake et al. (2018) argued that women, labor companions, and health professionals find early labor difficult to manage and suggest that more effective communication with labor companions about the childbirth process may enhance their confidence in supporting laboring women. This is consistent with a Malawian study by Kululanga et al. (2012), a Swedish study by Ledenfors and Berterö (2016), and a study by Nash (2017) which explored how Australian men experienced the transition to fatherhood while attending father-only antenatal support/education groups.

Both this current research and other international studies suggest that new strategies for information sharing with expectant fathers about their role in childbirth should be identified along with the development of resources and ongoing professional training for midwives to promote culturally safe, father-inclusive practice.

Midwifery preparation of Australia's First Nations fathers must acknowledge their ways of knowing and preferred learning styles if it is to be culturally safe and effective. Western-style childbirth education classes are unlikely to be effective and would probably be counterproductive for Australia's First Nations fathers who are socioeconomically disadvantaged, have limited literacy and live in rural and remote areas. Preparation that involves storytelling, especially by other Australia's First Nations fathers, is culturally safer and likely to be more beneficial. By finding common ground between traditional culture and contemporary birthing 
practices, Australia's First Nations men might be better supported by midwives while retaining their essential cultural aspects of childbirth practices.

Limitations of this study include that the principal researcher and interviewer was known to be a staff member at the hospital where the research was conducted. This may have inhibited the participants from sharing negative experiences about the staff or hospital support.

The fact that all participants declined to be audiorecorded due to the personal nature of the questions posed a potential limitation. However, Pelto (2016) asserts that taping interviews does not guarantee excellent analysis and research quality. Hence, participants should not feel compelled to be recorded as this can compromise the accounts the researcher gathers (Pelto, 2016). Traditionally, in First Nations culture, it is inappropriate to establish eye contact during a conversation (Queensland Health, 2015). Therefore, in this research, handwritten notes taken during the interviews were acceptable. Participant's comments about the notes improved the trustworthiness of the data analysis and gave the researchers additional insights on the findings.

This research does not claim to be representative of all First Nations fathers in Australia nor the rest of the world. However, it does have the potential to initiate dialogues related to Australias First Nations expectant fathers' involvement in childbirth. Another key implication of this investigation is its potential to motivate midwives to work with First Nations expectant fathers to develop culturally appropriate support initiatives to empower this vulnerable but resilient population.

Recommendations for future research include the need to collect and analyze data related to the presence of Australia's First Nations being present with their partners during labor and birth. Future research needs to consider the birth outcomes of Australia's First Nations women who were supported by their partners. To investigate this, a more extensive study, using a larger sample is needed to evaluate the influence of Australia's First Nations father's engagement in birth outcomes. A mixed-methods methodology could answer research questions that a single approach cannot. Longitudinal, mixed-methods studies would be needed to ascertain any social impact for women, male partners, offspring, kin, and community.

The economic benefits and costs of Australia's First Nations expectant father's support on medical intervention rates, hospital stays, early discharge, and breastfeeding could be evaluated using a quantitative approach. In addition, qualitative information could be obtained through using visual methods such as photovoice, in conjunction with interviews. In accord with Affleck, Glass, and Macdonald (2012), Leal et al. (2018), and Radley (2011), the photovoice strategy may facilitate the collaboration and trust between the researcher and the participants, leading to a richer understanding of the research topic. It is possible that adding this approach to a future research methodology, might engage participants in a more critical dialogue around the research topic.

Future research could also be used to determine if different models of care (e.g., standard care, shared care, or continuity of care in the midwifery group practice) had an impact on the experiences of Australia's First Nations men supporting their partners during childbirth.

Depending on the outcomes of the future research outlined above, the results could guide policymakers to develop long-term support programs that could have enduring effects for each womans and her partner's health and mental well-being; child and community health in Australia's First Nations families.

\section{CONCLUSION}

The experience of the Australia's First Nations fathers participating in this study formed a bridge between their traditional ways of knowing and learning and their selfidentity as a new generation of fathers in Central Australia wanting and willing to support their partner during childbirth. The statement, "we show affection in different way" indicates that both partners wish to experience childbirth in a way that has not been recognized or experienced in previous generations. The experience of this self-identified new generation of First Nations fathers teaches us that they desire support and information to support their partners well. They reflected that the best ways of receiving information would be by complying with the traditional ways of learning - that is by observation and orally when it was said, "we are very good observers... you know, educate dads by telling stories about birth." This will require midwives and other maternity care professionals to rethink Western expectations of "childbirth education classes" and provision of written information if First Nations childbearing couples are to have their culturally unique requirements and needs optimally met. It is recommended that future research builds on this small study to explore who is best to share the information which the First Nations fathers desire and in what ways it is best shared. 


\section{REFERENCES}

Abalos, E. E., Rivera, R. Y., Locsin, R. C., \& Schoenhofer, S. O. (2016). Husserlian phenomenology and Colaizzi's method of data analysis: Exemplar in qualitative nursing inquiry using nursing as caring theory. International Journal for Human Caring, 20(1), 19-23. doi:10.20467/1091-5710-20.1.19

Affleck, W., Glass, K. C., \& Macdonald, M. E. (2012). The limitations of language: Male participants, stoicism, and the qualitative research interview. American Journal of Men's Health, 7(2), 155-162. doi:10.1177/1557988312464038

AQ2 Australian Health Ministers' Advisory Council. (2013). National maternity services capability framework. Commonwealth of Australia. Retrieved from https://www.health.gov.au/internet/main/publishing .nsf/content/.../\$File/capab.docx

Australian Institute of Health and Welfare. (2018). My hospitals. Retrieved from https://www.myhospitals.gov.au/browse-hospitals/nt

Bäckström, C., \& Hertfelt, W. E. (2011). Support during labour: First time fathers descriptions of requested and received support during the birth of their child. Midwifery, 27(1), 67-73. doi:10.1016/j.midw.2009.07.001

Ball, J. (2010). Indigenous fathers' involvement in reconstituting ' Circles of care". American Journal of Community Psychology, 45, 124-138. doi:10.1007/s10464-009-92931

Bar-Yam, N. B., \& Darby, L. (1997). Fathers and breastfeeding: A review of the literature. Journal of Human Lactation, 13(1), 45-50. doi:10.1177/089033449701300116

Beake, S., Chang, Y., Cheyne, H., Spiby, H., Sandall, J., \& Bick, D. (2018). Experiences of early labour management from perspectives of women, labour companions and health professionals: A systematic review of qualitative evidence. Midwifery, 57, 69-84. doi:10.1016/j.midw.2017.11.002

Bell, H. R. (1998). Conception and birth. In H. R. Bell (Ed.), Men's business, women's business: Spiritual role of gender in the world's oldest culture (pp. 35-48). Rochester, NY: Inner Traditions Bear.

Brown, A., Middleton, P., Fereday, J., \& Pincombe, J. (2016). Cultural safety and midwifery care for Aboriginal women. A phenomenological study. Women and Birth, 29, 196-202. doi:10.1016/j.wombi.2015.10.013. Retrieved from http://www.womenandbirth.org/article/S18715192(15)00333-9/pdf

Buist, A., Morse, C. A., \& Durkin, S. (2003). Men's adjustment to fatherhood: Implications for obstetric health care. Journal of Obstetric, Gynecologic, \& Neonatal Nursing, 32, 172-180. doi:10.1177/0884217503252127

Carlson, J., Edleson, J. L., \& Kimball, E. (2014). First-time fathers' experiences of and desires for formal support: A multiple lens perspective. Fathering, 12(3), 242-261. doi:10.3149/fth.1203.242

Carroll, R., \& Lack, B. (2013, April 7-10). Midwifery continuity of care for remote women: The central Australian experience. Presentation at the 12th National Rural Health Conference, Adelaide, Australia.

Carter, E., Lumley, J., Wilson, G., \& Bell, S. (2004). ' Alukura .. for my daughters and their daughters and their daughters'. A review of Congress Alukura. Australian and New Zealand Journal of Public Health, 28, 229-234. doi:10.1111/j.1467-842X.2004.tb00701.x

Coutinho, E., Antunes, J., Duarte, J., Parreira, V., Chaves, C., \& Nelas, P. (2016). Benefits for the father from their involvement in the labour and birth sequence. Procedia - Social and Behavioral Sciences, 217, 435-442. doi:10.1016/j.sbspro.2016.02.010

de Melo, R. M., \& de Brito, R. S. (2013). The fathers' perception about their presence in the labor room during the birth of their child: A descriptive study. Online Brazilian Journal of Nursing, 12, 596-598. doi:10.5935/16764285.20134470

David, M., Aslan, G., Siedentopf, J., \& Kentenich, H. (2009). Ethnic Turkish fathers in birth support roles in a Berlin labour and delivery room. Motives, preparation and incidence in a 10-year comparison. Journal of Psychosomatic Obstetrics \& Gynecology, 30(1), 5-10. doi:10.1080/01674820902829781

Dietsch, E., Martin, T., Shackleton, P., Davies, C., McLeod, M., \& Alston, M. (2011). Australian aboriginal kinship: A means to enhance maternal well-being. Women and Birth, 24(2), 58-64. doi:10.1016/j.wombi.2010.06.003

Dietsch, E., Shackleton, P., Davies, C., Alston, M., \& McLeod, M. (2010). 'You can drop dead': Midwives bullying women. Women and Birth, 23(2), 53-59. doi:10.1016/j.wombi.2009.07.002

Dlugosz, S. (2013). Fathers at birth: Experiences of their partner's presence during childbirth. Unpublished Honours thesis, Edith Cowan University. Retrieved from http://ro.ecu.edu.au/cgi/viewcontent.cgi? article $=1105 \&$ context=theses_hons

Durey, A., \& Thompson, S. C. (2012). Reducing the health disparities of Indigenous Australians: Time to change focus. BioMed Central Health Services Research, 12(151), 1-11. doi:10.1186/1472-6963-12-151

Eggermont, K., Beeckman, D., Hecke, A. V., Delbaere, I., \& Verhaeghe, S. (2017). Needs of fathers during labour and childbirth: A cross-sectional study. Women and Birth, 
30, e188-e197. doi:10.1016/j.wombi.2016.12.001

Etikan, I., Musa, S. A., \& Alkassim, R. S. (2016). Comparison of convenience sampling and purposive sampling. American Journal of Theoretical and Applied Statistics, 5(1), 14. doi:10.11648/j.ajtas.20160501.11

Hall, J., Case, A., \& O'Neill, L. (2015). Northern territory midwives' collection. Mothers and babies 2013. Department of Health, Darwin. Retrieved from http://digitallibrary.health.nt.gov.au/prodjspui/ bitstream/10137/640/1/Mother\%20and\%20Babies\%20 2013.pdf

Hartz, D., \& McGrath, L. (2017). Working with indigenous families. In G. Thomson \& V. Schmeid (Eds.), Psychosocial resilience and risk in the perinatal period: Implications and guidance for professionals (pp. 44-61). Oxon, England: Routledge.

He, H. G., Vehviläinen-Julkunen, K., Qian, X. F., SapountziKrepia, D., Gong, Y., \& Wang, W. (2015). Fathers' feelings related to their partners' childbirth and views on their presence during labour and childbirth: A descriptive quantitative study. Journal of Nursing Practice, 21(2), 71-79. doi:10.1111/ijn.12339

Hildingsson, I., Cederlöf, L., \& Widén, S. (2011). Fathers' birth experience in relation to midwifery care. Women and Birth, 24, 129-136. doi:10.1016/j.wombi.2010.12.003

Hollins, M. C. (2008). A tool to measure fathers' attitudes and needs in relation to birth. British Journal of Midwifery, 16(7), 432-437. doi:10.12968/bjom.2008.16.7.30463

AQ3 Howarth, A. M., Scott, K. M., \& Swain, N. R. (2017). First-time fathers' perception of their childbirth experience. Journal of Health Psychology, 1-12. doi:10.1177/1359105316687628

Johansson, M., Fenwick, J., \& Premberg, Å. (2015). A meta synthesis of fathers' experiences of their partner's labour and the birth of their baby. Midwifery, 31, 9-18. doi:10.1016/j.midw.2014.05.005

Kakaire, O., Kaye, D. K., \& Osinde, M. O. (2011). Male involvement in birth preparedness and complication readiness for emergency obstetric referrals in rural Uganda. Reproductive Health, 8(12), 1-7. doi:10.1186/1742-4755-8-12

Kaye, D. K., Kakaire, O., Nakimuli, A., Osinde, M. O., Mbalinda, S. N., \& Kakande, N. (2014). Male involvement during pregnancy and childbirth: Men's perceptions, practices and experiences during the care for women who developed childbirth complications in Mulago Hospital, Uganda. BioMed Central Pregnancy and Childbirth, 14(54), 1-8. doi:10.1186/1471-2393-1454

Kildea, S., Hickey, S., Nelson, C., Currie, J., Carson, A., Reynolds, M., \& Tracy, S. (2017). Birthing on country (in our community): A case study of engaging stakeholders and developing a best-practice Indigenous maternity service in an urban setting. Australian Health Review, 42, 230-238. doi:10.1071/AH16218

Kildea, S., Tracy, S., Sherwood, J., Magick-Dennis, F., \& Barclay, L. (2016). Improving maternity services for Indigenous women in Australia: Moving from policy to practice. The Medical Journal of Australia, 205(8), 374-379. doi:10.5694/mja16.00854

Kululanga, L. I., Malata, A., Chirwa, E., \& Sundby, J. (2012). Malawian fathers' views and experiences of attending the birth of their children: A qualitative study. BioMed Central Pregnancy and Childbirth, 12(141), 110. doi:10.1186/1471-2393-12-141

Leal, C. C. G., Gomes-Sponholz, F. A., Mamede, F. V., Silva, M. A. I., Oliveira, N. T. B., \& Leite, A. M. (2018). Photovoice: Method experiment research with adolescent mothers. Escola Anna Nery, 22(3), 1-7. doi:10.1590/2177-9465-EAN-2017-0322

Ledenfors, A., \& Berterö, C. (2016). First-time fathers' experiences of normal childbirth. Midwifery, 40, 26-31. doi:10.1016/j.midw.2016.05.013

Longworth, H., \& Kingdon, C. (2011). Fathers in the birth room: What are they expecting and experiencing? A phenomenological study. Midwifery, 27, 588-594. doi:10.1016/j.midw.2010.06.013

Longworth, M. K., Furber, C., \& Kirk, S. (2015). A narrative review of fathers' involvement during labour and birth and their influence on decision making. Midwifery, 3, 844-857. doi:10.1016/j.midw.2015.06.004

Luo, K., Kueh, B., Jeffery, T., Petersen, R. W., \& Quinlivan, J. A. (2014, April). Australian father's study: What attitudes and roles do expectant Aboriginal fathers adopt in antenatal care decision-making? Paper presented at the Perinatal Society of Australia and New Zealand Annual Scientific Conference. doi:10.13140/2.1.2175,3928

Machin, A. J. (2015). Mind the gap: The expectation and reality of involved fatherhood. Fathering, 13(1), 36-59. doi: $10.3149 /$ fth.1301.36

Nappaljari, J. (2013). Birthing: Aboriginal women. Journal of Indigenous Policy, 13. Retrieved from http://www5.austlii.edu.au/au/journals/JlIndigP/2012/8 .pdf

AQ5

Nash, M. (2017). "It's just good to get a bit of man-talk out in the open": Men's experiences of father-only antenatal preparation classes in Tasmania, Australia. Psychology of Men \& Masculinity. doi:10.1037/men00001Q2

Nation Master. (2018). Geography. Land area. Square kilometres. Countries Compared. Retrieved from http://www.nationmaster.com/countryinfo/stats/Geography/Land-area/Sq.-km 
Northern Territory Government. (2017). Birthing services in central Australia.. Retrieved from https://nt.gov.au/wellbeing/pregnancy-birthingand-child-health/birthing-services-centralaustralia/introduction

Odent, M. (2009). The masculinization of the birth environment. Journal of Prenatal and Perinatal Psychology and Health, 23(3), 185-191. Retrieved from https://birthpsychology.com/journal/article/ masculinisation-birth-environment

Parker, S., McKinnon, L., \& Kruske, S. (2014). 'Choice, culture and confidence': Key findings from the 2012 having a baby in Queensland Aboriginal and Torres Strait Islander survey. BioMed Central Health Services Research, 14(196), 1-12. doi:10.1186/1472-6963-14-196

Pelto, P. J. (2016). Applied ethnography: Guidelines for field research. London, England: Routledge.

Premberg, Å, Carlsson, G., Hellström, A., \& Berg, M. (2011). First-time fathers' experiences of childbirth. A phenomenological study. Midwifery, 27(6), 848-853. doi:10.1016/j.midw.2010.09.002

Prichep, D. (2017, June 18). This father's day, remembering a time when dads weren't welcome in delivery rooms. Health News from National Public Radio. Retrieved from https://www.npr.org/sections/healthshots/2017/06/18/532921305/this-fathers-dayremembering-a-time-when-dads-werent-welcome-indelivery-rooms

Pryor, J., Morton, S., Bandara, D., Robinson, E., \& Grant, C. (2014). Pregnant partners: Fathers of the growing up in New Zealand children. Journal of Family Studies, 20(1), 5-18. doi:10.5172/jfs.2014.20.1.5

AQ7 Queensland Health. (2015). Communicating effectively with Aboriginal and Torres Strait Islander people. Retrieved from https://www.health.qld.gov.au/_data/assets/pdf_file/ 0021/151923/communicating.pdf

Radley, A. (2011). Image and imagination. In P. Reavey (Ed.), Visual methods in psychology: Using and interpreting images in qualitative research (pp. 17-28). New York, NY: Taylor and Francis.

Reibel, T., Morrison, L., Griffin, D., Chapman, L., \& Woods, H. (2015). Young aboriginal women's voices on pregnancy care: Factors encouraging antenatal engagement. Women \& Birth, 28(1), 47-53. doi:10.1016/j.wombi.2014.10.003

Sapkota, S., Kobayashi, T., \& Takase, M. (2012). Husbands' experiences of supporting their wives during childbirth in Nepal. Midwifery, 28, 45-51. doi:10.1016/j.midw.2010.10.010
L, Sengane. M. (2009). The experience of black fathers concerning support for their wives/partners during labour. Curationis, 32(1), 67-73. doi:10.4102/curationis.v32i1.889

Simmonds, D., West, L., Porter, J., Davies, M., Holland, C., Preston-Thomas, A., . . . Tangey, A. (2012). The role for support person for Ngaanyatjarra women during pregnancy and birth. Women and Birth, 25, 79-85. doi:10.1016/j.wombi.2010.12.007

Smythe, L. (2012). Discerning which qualitative approach fits best. New Zealand College of Midwives, 46, 5-12.

Sovereign, Union. (2016). The difference between the 'First Australians' and the 'First Nations'. Retrieved from http://www.nationalunitygovernment.org/content/ difference-between-first-australians-and-first-nations

Varcoe, C., Brown, H., Calam, B., Harvey, T., \& Tallio, M. (2013). Help bring back the celebration of life: A community-based participatory study of rural Aboriginal women's maternity experiences and outcomes. BioMed Central Pregnancy and Childbirth, 13(26), 1-10. doi:10.1186/1471-2393-13-26

Vehviläinen-Julkunen, K., \& Liukkonen, A. (1998). Fathers' experiences of childbirth. Midwifery, 14(1), 10-17. doi:10.1016/S0266-6138(98)90109-7

Disclosure. The authors have no relevant financial inter- AQ8 est or affiliations with any commercial interests related to the subjects discussed within this article.

Correspondence regarding this article should be directed AQ9 to Yordanka Berg Blanc, BN, PG Dip Midwifery, MSc Midwifery, Alice Springs Hospital, Maternity Unit, Po Box 3162, Alice Springs, NT 0871 Australia. E-mail: ybergblanc@gmail.com

Yordanka Berg Blanc, BN, PG Dip Midwifery, MSc Midwifery, Alice Springs Hospital, Maternity Unit, Alice Springs, Northern Territory, Australia.

Elaine Dietsch, RM PhD, Griffith University, School of Nursing and Midwifery, Nathan Queensland, Australia. 


\section{Author Queries:}

AQ1: AU: Please suggest whether units with numbers needs to be abbreviated.

AQ2: AU: Please provide valid URL for “Australian Health Ministers' Advisory Council” (2013).

AQ3: AU: Please provide volume number for Howarth et al. (2017).

AQ4: AU: Please provide conference location for Luo et al. (2014).

AQ5: AU: Please provide page range for Nappaljari (2013).

AQ6: AU: Please provide volume number and page range for Nash (2017).

AQ7: AU: Please provide valid URL for Queensland Health (2015).

AQ8: AU: Please confirm the accuracy of the Disclosure statement.

AQ9: AU: Please confirm whether updated correspondence details are appropriate. 